\title{
On the Valuation and Incentive Effects of Executive Cash Bonus Contracts*
}

\author{
Lionel Martellini ${ }^{\dagger}$ and Branko Urošević
}

December 1, 2003

\begin{abstract}
Executive compensation packages are often valued in an inconsistent manner: while employee stock options (ESOs) are typically valued ex-ante, cash bonuses are valued ex-post. This renders the existing valuation models of employee compensation packages theoretically unsatisfactory and, potentially, empirically distortive. In this paper, we propose an option-based framework for ex-ante valuation of cash bonus contracts. After obtaining closed-form expressions for ex-ante values of several frequently used types of bonus contracts, we utilize them to explore the effects that the shape of a bonus contract has on the executive's attitude toward risk-taking. We, also, study pay-performance sensitivity of such contracts. We show that the terms of a bonus contract can dramatically impact both risk-taking behavior as well as pay-performance incentives. Several testable predictions are made, and venues of future research outlined. Key words: Executive Compensation, Cash Bonus, Incentives, Risk-Taking Behavior. Word count: 6602. JEL classification: J33; G13.
\end{abstract}

*We would like to thank Kevin Murphy and Nick Wonder for their very useful comments. All errors are, of course, the authors' sole responsibility.

$\dagger$ EDHEC Graduate School of Business and EDHEC Risk and Asset Management Research Center, 1090 route des Crêtes, 06560 Valbonne, France. Tel: 33 (0)4 929689 50. Email: lionel.martellini@edhec.edu.

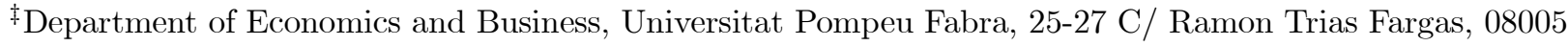
Barcelona, Spain. Also affiliated with CREA (Barcelona, Spain), and SECCF (Belgrade, Serbia-Montenegro). Phone: +34 93542 2590. Email: branko.urosevic@upf.edu. We would like to thank Kevin Murphy and Nick Wonder for their very useful comments. All errors are, of course, the authors' sole responsibility. 


\section{Introduction}

The compensation of top corporate executives is a popular topic of discussion in both business and academic circles. Some of the more frequently discussed issues are: the most appropriate structure and level of an executive compensation package, how the structure of a compensation package influences managers' attitudes toward risk-taking, and how the structure of the compensation package relates to the firm's performance. Regarding the first issue, Holmstrom (1979) argues that an optimal compensation contract should ensure the maximum expected utility for the principal (the shareholders) while providing at least the reservation level of the expected utility for the agent (the executive). This approach has subsequently been adopted in the vast literature on the optimal principal-agent risk-sharing rules. The connection between the structure of the compensation package and the agent's attitude toward risk is explored, for example, in Ross (1999) and Carpenter (2000). These papers show that, for a risk-averse manager, adding a convex-shaped compensation contract does not always increase a manager's desire to take risk. The relationship between the level of the executive compensation and the firm's performance is addressed in a seminal paper by Jensen and Murphy (1990) \{see also Garen (1994), and many follow-up papers $\}.{ }^{1}$ The predictive power of such studies, and their ability to test agency problems, is conditional upon the correct measurement of the level and sensitivity of the compensation. In that respect, the valuation problem is primitive with respect to the exploration of agency issues.

Compensation contracts are increasingly complex packages with an underlying option-like structure (see Table 1$).^{2}$

\begin{tabular}{llll}
\hline & Underlying Asset & Expiration Date & Early Exercise \\
\hline Base Salary & Cash & None & N/A \\
Restricted Stock & Stock & None & N/A \\
Cash Bonus & Perf. measure(s) & 1 year & No \\
Long-Term Bonus & Perf. measure(s) & $3-6$ years & No \\
Stock Option & Stock & 10 years & Yes \\
\hline \hline
\end{tabular}

Table 1: The Underlying Option Structure of a Typical Executive Compensation Contract

It would seem natural, therefore, to value compensation contracts using option pricing techniques. However, the valuation techniques used in the academic literature are often not selfconsistent: while employee stock option (ESO) grants are typically valued ex-ante, i.e., before

\footnotetext{
${ }^{1}$ Hermalin and Wallace (1999) and Murphy (1999) provide a comprehensive review of the literature on the subject.

${ }^{2}$ The complexity of the compensation contracts is documented in Kole (1997), Murphy (1999), and Hermalin and Wallace (1999), among others.
} 
uncertainties are resolved \{see, for example, Carpenter (1998)\}, cash bonuses are systematically valued ex-post, i.e., by taking a discounted value of the realized cash grants. Such lack of consistency can distort empirical results. A related, yet mostly overlooked problem is that when ex-post valuation is utilized, pay-performance sensitivity measures such as the one introduced in Jensen and Murphy (1990) \{see Section 3.2 of the present paper for more details\} are not well defined.

Consistent use of ex-ante valuation for all components of a compensation package would simultaneously resolve both of these problems and provide a natural framework for the analysis of agency problems. Despite its obvious merits, ex-ante valuation of cash bonus grants has not been explored in the literature until now, primarily because the ex-post approach is much simpler to use in empirical studies. ${ }^{3}$ Ex-ante valuation requires knowledge of both the contract structure (performance measures, the pay-for-performance relationship, etc.) and the probability distribution of the performance variables. Since the performance is typically measured by accounting variables, that is not an easy task.

The aim of this paper is to initiate the development of an ex-ante valuation method for cash bonus packages. ${ }^{4}$ More precisely, we perform an ex-ante valuation as if the executive's performance were measured by the company's stock price, demonstrate how the shape of the bonus contract influences the executive's attitude toward risk, and study the pay-performance sensitivity of such contracts. We start by demonstrating that a typical executive bonus contract with a linear incentive zone has a payoff structure equivalent to a portfolio of standard and binary European call options (see Figure 1). As a result, under suitable assumptions (see assumptions (1) to (6) in Section 2), the ex-ante contract value is given by the linear combination of Black and Scholes and binary European call option prices (see, for example, Wilmott (1998)), with the strike prices at the boundary points of the incentive zone. Assuming that a risk neutral executive can choose the level of stock price volatility by selecting a set of projects at origination, we show that only deeply out-of-the-money contracts and contracts with a large incentive range (i.e., the large difference between the maximum and the minimum bonus payoffs) motivate a risk-neutral executive to take a non-negligible level of risk. The pay-performance sensitivity of a bonus package is, then, defined as the marginal change in the ex-ante contract value in response to a small change in the performance measure (i.e., the stock price). Our results are extended to bonus contracts with non-linear incentive zones, and performance share contracts with vesting risk. Several testable predictions are made, and some venues of future research outlined.

\footnotetext{
${ }^{3}$ Practitioners often use the expected or "target" bonus measure instead. That corresponds to an ex-ante valuation if the convexity of the bonus contract payoff is ignored. We thank K. Murphy for pointing this out to us.

${ }^{4}$ To the best of our knowledge, this is the first attempt to do so.
} 
This paper is organized as follows. In Section 2, we describe the structure of a typical cash bonus contract and obtain a closed-form expression for the value of a short-term bonus contract with a linear incentive zone. Section 3 explores the impact of a cash bonus contract on the executive's risk-taking behavior and incentives. In Section 4, we extend our approach to some other types of cash bonus contracts. Section 5 contains our conclusions and suggestions for the future research. In the Appendix, the reader can find details of a proof.

\section{The Incentive Schedule of a Typical Cash Bonus Con- tract}

The vast majority of executive bonus plans are based on an explicit incentive schedule. ${ }^{5} \mathrm{~A}$ common shape of the incentive curve is presented on Figure $1:^{6}$ an executive receives an amount $B_{l}$ if the performance measure reaches the minimal value $M_{l}$; exceeding $M_{l}$ increases the payoff to the executive in a linear fashion until it caps at $B_{u}$ when the performance measure reaches $M_{u} \cdot{ }^{7}$ Table 2 demonstrates that the following portfolio: $B_{l}$ long binary call options with a strike price $K=M_{l}, \frac{B_{u}-B_{l}}{M_{u}-M_{l}}$ long standard European call options with the strike price $K=M_{l}$ and $\frac{B_{u}-B_{l}}{M_{u}-M_{l}}$ short standard European call options with the strike price $K=M_{u}$, replicates the shape of the incentive curve on Figure 1. We shall refer to this portfolio as the replicating option portfolio.

\begin{tabular}{cccc}
\hline Payoff & $M_{T}<M_{l}$ & $M_{l} \leq M_{T}<M_{u}$ & $M_{T} \geq M_{u}$ \\
\hline Binary options & 0 & $B_{l}$ & $B_{l}$ \\
Long position in call option & 0 & $\frac{B_{u}-B_{l}}{M_{u}-M_{l}}\left(M_{T}-M_{l}\right)$ & $\frac{B_{u}-B_{l}}{M_{u}-M_{l}}\left(M_{T}-M_{l}\right)$ \\
Short position in call option & 0 & 0 & $-\frac{B_{u}-B_{l}}{M_{u}-M_{l}}\left(M_{T}-M_{u}\right)$ \\
\hline Total & 0 & $B_{l}+\frac{M_{T}-M_{l}}{M_{u}-M_{l}}\left(B_{u}-B_{l}\right)$ & $B_{u}$ \\
\hline \hline
\end{tabular}

Table 2: Replicating Option Portfolio Payoffs

Throughout this paper we maintain the following set of assumptions : (1) the executive's performance is measured by the company's stock price; (2) the executive is a risk-neutral expected utility maximizer; (3) the compensation contract consists of a fixed salary and a cash bonus contract; (4) there are no arbitrage opportunities; (5) the company's stock is

\footnotetext{
${ }^{5}$ See Murphy (1998) and Murphy (1999). These articles utilize the survey provided in "Annual Incentive Plan Design Survey" by Towers Perrin (1996-97).

${ }^{6}$ Among the compensation specialists, such bonus contract shape is known as the 80-120 Rule. The name comes from the typical values (as percentages of the target performance) of the lower and the upper performance bounds. See Murphy (1999).

${ }^{7}$ Convex as well as concave incentive zones are sometimes used as well. See Murphy (1998) and Section 4.1 for more details.
} 
traded continuously and without friction; and (6) the stock price follows a geometric Brownian motion.

Assumption (3) is introduced in order to isolate the effects of a bonus contract on the executive's risk-taking and pay-performance incentives. Real-life contracts usually have a number of other components (see Table 1). Accounting for contract complexity is not difficult. For example, while adding stock options would certainly change the risk-taking attitude of a risk-neutral executive, we can still use the same method of analysis as the one outlined in Section $3 .^{8}$ Assumptions (4) to-(6) are standard in the option pricing literature and could easily be relaxed.

Assumptions (1) and (2) are particularly important for tractability, even if not entirely realistic. ${ }^{9}$ More specifically, assuming that company performance is measured by the company's stock price (assumption (1)) allows us to rely on the standard complete markets option pricing techniques. In reality, performance in cash bonus contracts is primarily measured by accounting variables. ${ }^{10}$ Using accounting variables instead of the stock price would complicate valuation in two ways: probability distributions of the accounting variables are much less studied than the probability distributions of stock prices; in addition, and perhaps more importantly, there are no marketed securities with payoffs perfectly correlated with accounting variables. As a result, the standard option pricing techniques do not apply in a straightforward manner. ${ }^{11}$ Assumption (2) ensures that the company cost and the executive value of a compensation package coincide. In reality, executives are likely to be risk averse. In that case, the company cost, i.e., the amount of cash that a well-diversified outside investor would be willing to pay for such contingent claim, would be different from the value to the executive, i.e., the value that a risk-averse executive places on the same contract. ${ }^{12}$ The cost to the company can be obtained using the standard risk-neutral pricing techniques (see Section 2), while the value to a risk-averse executive, is, in general, impossible to find in closed form (see Lambert et al (1991) and Hall and Murphy (2000)). For a risk-neutral executive, however, the company

\footnotetext{
${ }^{8}$ For a risk-neutral executive, valuation of complex packages is additive \{see Urošević (2000) for a unified framework for the ex-ante valuation of complex compensation packages\}.

${ }^{9}$ In Martellini and Urošević (2001), we develop a consumption-based asset pricing model that allows us to relax the assumptions (1)-(3) and value complex compensation grants, including cash bonus contracts, from a risk-averse executive's perspective, when performance is measured by either the stock price or an accounting variable.

${ }^{10}$ Murphy (1998) reports that only five out of 177 contracts in his sample of the top U.S. companies used the stock price as a performance measure, but always coupled with one or more accounting measures.

${ }^{11}$ In contrast, if the performance is measured in terms of the company's stock price, the market is dynamically complete and the standard option pricing methods apply \{see Duffie (1995), for example\}.

${ }^{12}$ The main reason for the inefficiency is that, for an equity-based compensation contract, managers are rewarded by the market only for the systematic and not for the company-specific component of the risk they bear. The latter can be quite substantial for poorly diversified managers.
} 
cost and the executive value of a compensation contract coincide. This simplifies the problem significantly.

Since the company's stock price $S_{t}$ is assumed to be the sole performance measure, if the incentive zone is linear, the bonus payoff at maturity of the contract $T$ is given by the following formula:

$$
\operatorname{Payoff}(T)=B_{l} \mathbf{1}_{\left\{S_{T} \geq S_{l}\right\}}+\frac{B_{u}-B_{l}}{S_{u}-S_{l}}\left(\max \left(S_{T}-S_{l}, 0\right)-\max \left(S_{T}-S_{u}, 0\right)\right)
$$

When the shape of the incentive zone is linear, we denote the ex-ante value of the contract by $V_{l i n} \cdot{ }^{13}$ Taking the discounted expectation of the payoff (Equation 1) with respect to the risk-neutral probability measure, $V_{\text {lin }}$ can be expressed in terms of the standard and binary European call option prices:

$$
V_{\text {lin }}=B_{l} C_{B}\left(S_{0}, r, \sigma, T, K=S_{l}\right)+\frac{B_{u}-B_{l}}{S_{u}-S_{l}}\left(C\left(S_{0}, r, \sigma, T, K=S_{l}\right)-C\left(S_{0}, r, \sigma, T, K=S_{u}\right)\right)
$$

where the expressions in Equation (2) read: ${ }^{14}$

$$
\begin{aligned}
C\left(S_{0}, r, \sigma, T, K\right) & =S_{0} N\left(d_{1}\right)-K e^{-r T} N\left(d_{2}\right) \\
C_{B}\left(S_{0}, r, \sigma, T, K\right) & =e^{-r T} N\left(d_{2}\right)
\end{aligned}
$$

and

$$
\begin{aligned}
& d_{1}=\frac{\ln \left(\frac{S_{0}}{K}\right)+\left(r+\frac{1}{2} \sigma^{2}\right) T}{\sigma \sqrt{T}} \\
& d_{2}=d_{1}-\sigma \sqrt{T}
\end{aligned}
$$

Here, the current stock price is denoted as $S_{0}, r$ is the annual continuously compounded risk-free rate of return, and $\sigma$ is the stock price volatility.

\section{The Effects of a Bonus Contract on the Executive's Risk-Taking Behavior and Incentives}

Several papers discuss the effects of the shape of the bonus contract (Figure 1) on executives' motivation to manipulate the measures used in determining their bonus payoffs (corporate income, for example). ${ }^{15}$ The ex-ante valuation approach provides us with a natural framework

\footnotetext{
${ }^{13}$ In contrast, we use $V_{f}$ to denote the ex-ante value of the bonus contract when the shape of the incentive zone is given by a function $f$ that may not be linear (see Section 4.1).

${ }^{14}$ See Wilmott (1998), for example.

${ }^{15}$ See Healy (1985), Gaver, Gaver, and Austin (1995), Holthausen, Larcker, and Sloan (1995), and Murphy (1998).
} 
for addressing and quantifying agency problems. In particular, utilizing Equation 2, we show that if performance is measured by the stock price, the shape of the bonus contract curve plays an important role in shaping the executive's attitude towards risk; it also influences the executive's pay-performance sensitivity.

\subsection{Impact on the Executive's Risk-Taking Behavior}

Since Jensen and Meckling (1976), several studies have analyzed the impact of executive compensation contracts on the executive's attitude toward risk taking. More recently, Ross (1999) showed that adding a new contract into an executive's contract package causes a change in the executive's attitude toward risk that can be broken down into three component effects: convexity, magnification and translation. ${ }^{16}$ In the case of a risk-neutral executive assumption (2)\}, the translation and magnification effects vanish. As a result, the incremental impact on the executive's risk attitude is purely determined by the shape (convexity) of the contract. In this case, adding convexity to a contract leads to greater risk-taking on behalf of the executive. Since a performance-based cash bonus contract has a relatively complex option structure, it is natural to wonder what kind of attitude towards risk does granting a bonus contract generate. In order to facilitate such an analysis, we make the following, and final, assumption: (7) The executive can control the stock price volatility by selecting a portfolio of projects at the origination of the contract. ${ }^{17}$ From assumptions (1)-(7), it follows that the executive selects an optimal level of volatility at the origination of the contract so as to maximize the ex-ante value of her bonus contract. Note that, for simplicity, we are considering one-time volatility adjustments in this paper. Clearly, one could consider dynamic volatility adjustments, instead $^{18}$

Let us introduce some useful concepts. Let us define, for a compensation contract $X$, the value function as the map $\sigma \rightarrow V_{X}(\sigma)$, i.e., a function that plots the ex-ante values of the compensation contract for every level of volatility, ceteris paribus. We say that a contract $X$ leads to cautious behavior if $\lim _{\sigma \rightarrow \infty} V_{X}(\sigma)=0$ (otherwise, we call the executive's behavior non-cautious). If $X$ leads to cautious behavior, a value maximizing executive who is granted such contract would not have an incentive to increase volatility without bound. We say that

\footnotetext{
${ }^{16}$ For a risk-averse agent with decreasing absolute risk aversion (DARA) preferences, Ross (1999) shows that adding a call option may actually increase her risk aversion. Similar, even if somewhat weaker, conclusions are reached in a dynamic model by Carpenter (2000). She demonstrates that receiving a stock option compensation grant would not lead a fund manager with a constant relative risk aversion (an example of DARA preferences) to always seek greater risk.

${ }^{17}$ Johnson and Tian $(2000 \mathrm{a}, 2000 \mathrm{~b})$ make the same assumption in analyzing risk-taking incentives generated by employee stock option contracts. See, also, Jiang (2000) for a principal-agent model where the agent privately and effortlessly controls risk.

${ }^{18}$ Cadenillas et al (2001) price executive stock options allowing for dynamic volatility adjustments.
} 
a contract leads to non-trivial risk taking behavior if the value function is not monotonically decreasing in volatility (otherwise, it leads to trivial risk-taking behavior). Finally, we say that a contract leads to optimal risk-taking behavior if the corresponding value function has the interior global maximum as a function of volatility (and suboptimal otherwise).$^{19}$ Establishing whether the bonus contract (Figure 1) leads to an optimal risk-taking behavior is, therefore, equivalent to establishing whether the corresponding value function has a global maximum at a non-zero, finite level of volatility. When the global interior maximum exists and is reached at $\sigma=\sigma^{*}$, it is in the executive's best interest to take up risk until $\sigma^{*}$ is reached. Any further increase (or decrease) in risk would decrease the ex-ante value of her contract. Thus, a rational executive would choose would select a project that leads to $\sigma=\sigma^{*}$. Clearly, contracts that lead to non-cautious or trivial behavior cannot lead to optimal risk-taking behavior (in the sense defined above).

\subsubsection{Value Functions for Benchmark Contracts}

In this section we determine the shape of the value functions for a set of benchmark contracts which are the "building blocks" of a typical cash bonus contract (see Table 3).

\begin{tabular}{lll}
\hline Contract Type & Payoff at Expiration & Ex-ante Company Cost at Origination \\
\hline Stock & $S_{T}$ & $V_{\text {stock }}=S_{0}$ \\
Binary Option & $B_{l} \mathbf{1}_{\left\{S_{T}-S_{l}\right\}}$ & $V_{\text {binary }}=B_{l} C_{B}\left(S_{0}, r, \sigma, T, K=S_{l}\right)$ \\
Stock Option & $\max \left(S_{T}-S_{l}, 0\right)$ & $V_{\text {option }}=C\left(S_{0}, r, \sigma, T, K=S_{l}\right)$ \\
Unlimited Upside Potential & $B_{l} \mathbf{1}_{\left\{S_{T}-S_{l}\right\}}+\max \left(S_{T}-S_{l}, 0\right)$ & $V_{\text {unlim }}=B_{l} C_{B}\left(K=S_{l}\right)+C\left(K=S_{l}\right)$ \\
\hline \hline
\end{tabular}

Table 3: Benchmark Contracts

In the case of a stock grant, the expression $V_{\text {stock }}=S_{0}$ implies that $\frac{\partial V_{\text {stock }}}{\partial \sigma}=0$ for every $\sigma$. In other words, the value function is flat. That, in turn, implies that the executive is indifferent regarding any particular value of volatility, including the most extreme high or low values.

For the other benchmark contracts, it is useful to distinguish between the two types of contracts: Type I contract, for which $S_{0}<S_{l} e^{-r T}$, and the Type II contract, for which $S_{0} \geq S_{l} e^{-r T}$. If we define the quantity $a \equiv \ln \left(\frac{S_{l}}{S_{0}}\right)-r T$, then a contract for which $a>0$ corresponds to a Type I, while a contract for which $a \leq 0$ corresponds to a Type II contract. Depending upon the contract type, the desire to maximize the contract value may influences the executive's attitude toward risk differently. The following proposition states that Type I contracts are worthless (ex-ante) for an executive who does not take any risk.

\footnotetext{
${ }^{19}$ Optimal risk-taking behavior does not have to be optimal in any other way; in particular, it can be sub-optimal from the shareholders' point of view (see Section 3.2).
} 
Proposition 1 For binary, stock option, unlimited upside, and general cash bonus contracts, $\lim _{\sigma \rightarrow 0} V=0$ for Type I contracts and $\lim _{\sigma \rightarrow 0} V>0$ for Type II contracts.

$\mathbf{P}$ roof. The proof is immediate from $\lim _{\sigma \rightarrow 0} C=\max \left(S_{0}-K \exp (-r T), 0\right)$ and $\lim _{\sigma \rightarrow 0} C_{B}=$ $e^{-r T} \mathbf{1}_{S_{0}-S_{l} e^{-r T} \text {. }}$

For Type I contracts, it would be in the executive's best interest to undertake some risky projects. Therefore, Type I contracts always lead to non-trivial risk-taking behavior. In addition, for stock option contracts, the following proposition holds:

Proposition 2 a) $\lim _{\sigma \rightarrow \infty} V_{\text {option }}=S_{0}$.

b) $V_{\text {option }}(\sigma)$ is monotonically increasing as a function of $\sigma$, for all $\sigma$.

$\mathbf{P}$ roof. Part a) in Proposition 1 follows from $\lim _{\sigma \rightarrow \infty} C=S_{0}$. Part b) is immediate from $\frac{\partial V_{\text {option }}}{\partial \sigma}=S_{0} \sqrt{T} n\left(d_{1}\right)>0$.

Notice that, in this context, a stock option contract leads to non-cautious risk taking. ${ }^{20}$ Namely, it would be optimal for an executive to take on infinitely risky projects. ${ }^{21}$ In contrast, for a binary contract, the following proposition holds:

Proposition 3 a) $\lim _{\sigma \rightarrow \infty} V_{\text {binary }}=0$ for both Type I and Type II contracts.

b) For Type I contract, the value function has a unique global interior maximum at $\sigma^{*}=$ $\sqrt{\frac{2 a}{T}}>0$; otherwise, the value function $V_{\text {binary }}(\sigma)$ is monotonically decreasing.

$\mathbf{P}$ roof. Part a) of the Proposition follows from $\lim _{\sigma \rightarrow \infty} C_{B}=0$. Since $\frac{\partial V_{\text {binary }}}{\partial \sigma}=$ $-\frac{S_{0} B_{l}}{S_{l}} n\left(d_{1}\right) \frac{d_{1}\left(K=S_{l}\right)}{\sigma}$, where $n($.$) is the standardized normal probability density function and$ the fact that $\operatorname{sign}\left(\frac{\partial V_{\text {binary }}}{\partial \sigma}\right)=-\operatorname{sign}\left(d_{1}\left(K=S_{l}\right)\right)=-\operatorname{sign}\left(\frac{\sigma^{2} T}{2}-a\right)$, Part b) of the Proposition follows immediately.

Proposition 3 states that a binary contract leads to cautious behavior for both types of contracts; Type I contracts also lead to the existence of a global interior maximum, or "optimal" risk-taking behavior. On the other hand, since its upside potential is limited, a binary contract does not provide an incentive for an executive to raise her performance above the performance threshold.

The unlimited upside potential contract is, in effect, a combination of a binary contract and a stock option. In this case, the shape of the value function depends not only on the relation between the current stock price and the lower bound, but also on the ratio $b=\frac{B_{l}}{S_{l}}$, i.e., the relative size of the award for reaching the threshold. The following proposition holds:

\footnotetext{
${ }^{20}$ See Johnson and Tian (2000a) and (2000b) for a detailed discussion.

${ }^{21}$ For a risk-averse executive, Proposition 2, part b) would no longer hold \{see Hall and Murphy (2000b), and Martellini and Urošević (2001)\}.
} 
Proposition 4 a) $\lim _{\sigma \rightarrow \infty} V_{\text {unlim }}=S_{0}$ for both contract types.

b) i) When $a>0$ (Type I contract) and $b \leq 2, V_{\text {un } \lim }(\sigma)$ is monotonically increasing for all $\sigma$; if $a>0$ and $b>2$, a global interior maximum exists at $\sigma^{*}=\sqrt{\frac{2 a b}{(b-2) T}}>0$; ii) when $a=0, V_{\text {unlim }}(\sigma)$ is monotonically increasing if $b<2$, a constant if $b=2$, and monotonically decreasing if $b>2$; iii) when $a<0, V_{\text {unlim }}(\sigma)$ is monotonically decreasing if $b \geq 2$ and has a global interior minimum.

$\mathbf{P}$ roof. Part a) is immediate from the proofs of the Propositions 2 and 3. Part b) follows from $\operatorname{sign}\left(\frac{\partial V_{\text {unlim }}}{\partial \sigma}\right)=\operatorname{sign}\left(\frac{\sigma \sqrt{T} S_{l}}{B_{l}}-d_{1}\left(K=S_{l}\right)\right)=\operatorname{sign}\left(a+\left(\frac{1}{b}-\frac{1}{2}\right) \sigma^{2} T\right)$.

Notice that a contract with an unlimited upside potential always leads to cautious behavior only when $b>2$, i.e., when the reward for reaching the lower performance bound is sufficiently high with respect to the bound itself; only Type I contracts within that class lead to an optimal risk-taking behavior.

We now turn to a similar analysis for the general cash-bonus contract (see Figure 1) which, in contrast to the unlimited upside potential contract has an added performance cap feature.

\subsubsection{The Value Function for a Cash-Bonus Contract}

From Proposition 1 we know that Type I contracts are worthless (ex-ante) to an executive who does not take any risk, while Type II contracts are not. We now demonstrate that, because of the performance cap, a typical bonus contract (Figure 1) leads to cautious behavior for all values of the relative award for reaching the threshold, $b$. In addition, the class of contracts that induce "optimal" risk taking behavior is wider than for any of the benchmark contracts. In order to prove this, let us introduce two subcategories for the Type II class of contracts: those for which $S_{l} e^{-r T}<S_{0} \leq S_{u} e^{-r T}$ (Type Ila contracts) and those for which $S_{0}>S_{u} e^{-r T}$ (Type IIb contracts). The following proposition describes the shape of the value function:

Proposition 5 a) $\lim _{\sigma \rightarrow \infty} V_{\text {lin }}=0$ for each contract type.

b) For a Type I contract, the value function has one extreme point, the global interior maximum.

c) If $S_{0} \geq S^{*}=\sqrt{S_{u} S_{l}} e^{-r T}$ (i.e., for all Type IIb and some Type IIa contracts), the value function is monotonically decreasing in volatility.

d) For a Type IIa contract where $S_{0}<S^{*}$, the shape of the value function depends on the lower and upper bonus payoffs, $B_{l}$ and $B_{u} \cdot{ }^{22}$ If $B_{l}=0$, the value function has one extreme point, the global interior maximum; if $B_{l} \neq 0$ and $B_{u}-B_{l}$ is relatively "small" with respect to

\footnotetext{
${ }^{22}$ The values of $S_{0}, S_{l}$, and $S_{u}$ are assumed to be fixed.
} 
$B_{l}$, the value function is a monotonically decreasing function of volatility; ${ }^{23}$ for intermediate values of $B_{u}-B_{l}$ with respect to $B_{l}$, there are two extreme points, a local interior minimum at $\sigma=\sigma_{\min }$, and a local interior maximum at $\sigma=\sigma_{\max }$, so that $\sigma_{\min }<\sigma_{\max }$. The maximum is global for sufficiently large values of $B_{u}-B_{l}$ with respect to $B_{l}$.

$\mathbf{P}$ roof. See the Appendix.

In Figures 2-5, we plot the value function for each contract type and for various values of $B_{l}\left(B_{l}=0,0.1,0.2,0.3\right) .{ }^{24}$ We have used the following set of parameters: $T=1 ; r=5 \%$; $S_{l}=120 ; S_{u}=140$ and $B_{u}=.5$. Let us refer to $S_{0}=107,117$, and 127 as the low, intermediate, and high current stock price values corresponding to contract types I, IIa, and IIb, respectively. ${ }^{25}$ From Proposition 5, part a), we infer that a rational executive would have an incentive to be cautious in her risk-taking. In addition, we observe the following:

i) If the current stock price $S_{0}$ is low, illustrated by the curve where $S_{0}=107$ curve in Figures 2-5, the contract leads to "optimal" risk-taking behavior (Proposition 5, part b). The same is true for intermediate values of $S_{0}$, when the executive is paid only if she outperforms the lower bound (Proposition 5, part d)). This is illustrated by the curve where $S_{0}=117$ in Figure 2.

ii) For high values of the current stock price, illustrated by the curve where $S_{0}=127$ in Figures $2-5$, the contract leads to trivial risk-taking behavior or, in other words, to complete risk avoidance on the part of the executive (Proposition 5, part c)). The same is true for intermediate values of the current stock price, when $B_{l}>0$ and the incentive range $B_{u}-B_{l}$ is relatively small with respect to $B_{l}$, as illustrated by the curve where $S_{0}=117$ in Figure 5 (Proposition 5, part d)).

iii) The situation is more intricate for the intermediate values of the current price for which $S_{0}<S^{*}$, as illustrated by $S_{0}=117$ on Figures 3 and 4 (Proposition 5, part d)). When $B_{l}$ is positive, and $B_{u}-B_{l}$ is sufficiently large with respect to $B_{l}$ (Figure 3), there is a local minimum and a global interior maximum. Thus, the contract leads to "optimal" risk-taking behavior. In this case, after an initial decrease until $\sigma=\sigma_{\min }$, the value function rises as volatility increases, until a value $\sigma=\sigma_{\max }$ is reached. This point corresponds to the global maximum of the value function. Thus, a rational executive would select $\sigma=\sigma_{\max }$. In contrast, for intermediate values of $B_{u}-B_{l}$ with respect to $B_{l}$ (Figure 4 ), the internal maximum is only local, and not global, so the contract in this case leads to trivial risk-taking behavior (i.e., the executive does not undertake any risky projects at all).

\footnotetext{
${ }^{23}$ We use quotation marks for "small" since $B_{u}-B_{l}$ does not have to be small with respect to $B_{l}$ in an absolute sense; in our illustration, when $S_{0}=117, S_{l}=120$, and $S_{u}=140$, the contract induces trivial risk-taking behavior, for example, even when $B_{l}=1$ and $B_{u}-B_{l}=0.95$.

${ }^{24}$ Fixing $B_{l}$ and changing $B_{u}$ leads to qualitatively similar results as long as $B_{l}>0$.

${ }^{25}$ That follows from $S_{l} \exp (-r T) \approx 114.15, S_{u} \exp (-r T) \approx 133.17$, and $S^{*}=\sqrt{S_{u} S_{l}} e^{-r T} \approx 123.93$.
} 
From Proposition 5, it follows that the contracts that cause the executive to take nonzero, finite, amounts of risk are either deeply out of the money (Type I contracts), or not so deeply out of the money but such that the executive receives little or no payment at the lower bound with respect to the incentive range (Type IIa contracts with $S_{0}<S^{*}$ and low $B_{l}$ with respect to $B_{u}-B_{l}$ ). Other contract types lead to complete risk avoidance on the part of the executive, and therefore should not be often observed in practice. These are important testable predictions. ${ }^{26}$

\subsection{Pay-Performance Sensitivity}

An important advantage of ex-ante valuation is that it allows one to properly define the notion of the pay-performance sensitivity of a bonus contract. In contrast, if the value of a bonus contract is measured ex-post, the pay-performance sensitivity cannot be determined and therefore has to be assumed to take certain value (see Section 4.2 for a specific example).

From Jensen and Murphy (1990), we recall that the pay-performance sensitivity of a compensation contract is a measure of the impact of a marginal change in the performance measure (in our case, the stock price $S_{0}$ ) on the contract value or, in other words, the contract "delta". For the linear cash bonus contract, this definition leads to the following expression:

$$
\frac{\partial V_{l i n}}{\partial S_{0}}=B_{l} \delta_{B}\left(K=S_{l}\right)+\frac{B_{u}-B_{l}}{S_{u}-S_{l}}\left(\delta\left(K=S_{l}\right)-\delta\left(K=S_{u}\right)\right)
$$

where deltas for the the standard and the binary call options are given by the following expressions: $:^{27}$

$$
\begin{aligned}
\delta & \equiv \frac{\partial C}{\partial S_{0}}=N\left(d_{1}\right) \\
\delta_{B} & \equiv \frac{\partial C_{B}}{\partial S_{0}}=\frac{e^{-r T} n\left(d_{2}\right)}{\sigma S_{0} \sqrt{T}}
\end{aligned}
$$

In Figure 6, we plot the contract value as a function of $S_{0}$. We observe that the contract values monotonically increase in $S_{0}$, ceteris paribus. Algebraically, this follows from that fact that $\delta$ is a decreasing function of $K$, and $\delta_{B}$ is non-negative. In other words, the payperformance sensitivity of a bonus contract is positive, as expected.

It is interesting to note that the scaled values of $\frac{\partial V_{l i n}}{\partial S_{0}}$, i.e., $2 \frac{\partial V_{l i n}}{\partial S_{0}} /\left(B_{l}+B_{u}\right)$, are relatively small for reasonable values of the parameters, and are typically much smaller than the corresponding option $\delta \equiv \frac{\partial C}{\partial S_{0}}=N\left(d_{1}\right) \cdot{ }^{28}$ While more careful analysis is needed, this likely implies

\footnotetext{
${ }^{26}$ For a risk-averse executive, one would expect the class of sub-optimal contracts to shrink, making Type II contracts more likely \{see Martellini and Urošević (2001)\}.

${ }^{27}$ See, for example, Willmott (1998).

${ }^{28}$ Varying the set of plausible parameters, we obtained a scaled value of cash bonus sensitivity typically less than 0.1 (and mostly around $0.02-0.04$ ).
} 
that bonus contracts have less pay-performance sensitivity than stock option contracts (and certainly less than the stock grants themselves). If this is true, why would one ever use a bonus package instead of stock options? The answer to this question could lie, in part, in the "optimal" risk-taking behavior implied by the bonus contract (Proposition 5), vis-a-vis non-cautious risk-taking behavior implied by the stock option contract (Proposition 2).

Let us end this sub-section by defining the agency problem which is potentially quite important. In general, the value of $\sigma$ that is optimal for the shareholders $\left\{\arg \max _{\sigma} \frac{\partial V_{\text {lin }}}{\partial S_{0}}(\sigma)\right\}$ does not coincide with the value of $\sigma$ that is optimal for the executive $\left\{\arg \max V_{\text {lin }}(\sigma)\right\}$. An "optimal" bonus contract, if it exists, would use the values of contract parameters that would achieve the optimal trade-off between the shareholders' and the executive's interests.

\subsection{The Impact of Contract Terms on Ex-Ante Valuation}

Let us now consider how changes in the contract terms set by the board of directors, namely, $B_{l}, B_{u}, S_{l}$ and $S_{u}$, influence the ex-ante value of the contract. The following proposition holds:

Proposition 6 a) Increases in $B_{l}$ and $B_{u}$ raise the value of the contract, while increases in $S_{l}$ and $S_{u}$ lower the value of the contract, ceteris paribus.

b) $\lim _{S_{u} \rightarrow S_{l}} V_{\text {lin }}=B_{u} C_{B}\left(S_{0}, r, \sigma, T, K=S_{l}\right)$.

$\mathbf{P}$ roof. The results of this Proposition follow immediately from the convexity and monotonicity of $C(K)$, as well as the fact that $C_{B}\left(K=S_{l}\right)=-\left.\frac{\partial}{\partial K} C(K)\right|_{K=S_{l}}$.

Intuitively, part a) of the Proposition says that increasing contractual payoffs, ceteris paribus, makes the executive better off; in contrast, raising their "performance plank" makes it less likely that the bonus will be paid, thus making the executive worse off, ceteris paribus. Part b) of the Proposition states that when the incentive domain $S_{u}-S_{l}$ is very small the contract essentially becomes just the binary option.

In addition, as Table 4 demonstrates, an increase in the incentive range $B_{u}-B_{l}$ raises the optimal level of risk that the executive would take. ${ }^{29}$

\begin{tabular}{cccccc}
\hline$B_{u}-B_{l}$ & 0.1 & 0.2 & 0.3 & 0.4 & 0.5 \\
\hline$\sigma^{*}$ for $S_{0}=107$ & $40 \%$ & $44 \%$ & $47 \%$ & $51 \%$ & $54 \%$ \\
$\sigma^{*}$ for $S_{0}=117$ & $0 \%$ & $0 \%$ & $20 \%$ & $27 \%$ & $33 \%$ \\
$\sigma^{*}$ for $S_{0}=127$ & $0 \%$ & $0 \%$ & $0 \%$ & $0 \%$ & $0 \%$ \\
\hline \hline
\end{tabular}

Table 4: Contract Value Arg Max as a Function of the Incentive Range

\footnotetext{
${ }^{29}$ Here, $T=1, r=5 \%, S_{l}=120, S_{u}=140, B_{u}=.5$, while $B_{l}$ varies from 0 to 0.4 . Qualitatively similar conclusions are reached if $B_{l}$ is fixed and $B_{u}$ varies, provided $B_{l}>0$.
} 
When an interior local minimum exists (for intermediate values of $S_{0}$ ), $\sigma_{\text {min }}$ decreases when the incentive range increases, as can be seen from Table 5 . Therefore, an increase in the incentive range widens the spread between $\sigma_{\max }$ and $\sigma_{\min }$.

\begin{tabular}{cccccc}
\hline$B_{u}-B_{l}$ & 0.1 & 0.2 & 0.3 & 0.4 & 0.5 \\
\hline$\sigma_{\min }$ & none & none & $6 \%$ & $4 \%$ & $0 \%$ \\
\hline \hline
\end{tabular}

Table 5: Contract Value ArgMin as a Function of the Incentive Range

A similar analysis for the change in pay-performance sensitivity with respect to changes in the contract terms can easily be performed.

\section{The Valuation of More General Cash Bonus Contracts}

In the previous sections, we only considered short-term bonus contracts with linear incentive zones (Figure 1). In this section we show how to value contracts with non-linear incentive zones as well as performance shares with vesting risk. We also provide an illustration of the potential magnitude of the difference between the ex-post and ex-ante value of a cash bonus contract.

\subsection{Non-linear Incentive Zones}

While a majority of cash bonus contracts have a linear incentive zone, there are also contracts with concave or convex incentive zones (see Figure 7 ). ${ }^{30}$

In that case, the contractual payoff at expiration depends on the terminal stock price $S_{T}$ through an increasing convex (concave) function $f\left(S_{T}\right)$ :

$$
\operatorname{Payoff}(T)=B_{l} \mathbf{1}_{\left\{S_{T} \geq S_{l}\right\}}+\frac{B_{u}-B_{l}}{f\left(S_{u}\right)-f\left(S_{l}\right)}\left[\max \left(f\left(S_{T}\right)-f\left(S_{l}\right), 0\right)-\max \left(f\left(S_{T}\right)-f\left(S_{u}\right), 0\right)\right]
$$

so that the expression for the contract value reads:

$$
\begin{aligned}
V_{f}= & e^{-r T} \mathbb{E}^{\mathbb{Q}}(\operatorname{Payoff}(T))=B_{l} C_{B}\left(S_{0}, r, \sigma, T, K=S_{l}\right) \\
& +\frac{B_{u}-B_{l}}{f\left(S_{u}\right)-f\left(S_{l}\right)}\left[C_{f}\left(S_{0}, r, \sigma, T, K=f\left(S_{l}\right)\right)-C_{f}\left(S_{0}, r, \sigma, T, K=f\left(S_{u}\right)\right)\right]
\end{aligned}
$$

Here, $C_{B}$ is a binary call option price $\{$ see Equation $(3)\}$, and

$$
C_{f}=e^{-r T} \mathbb{E}^{\mathbb{Q}}\left(\max \left(f\left(S_{T}\right)-K, 0\right)\right)
$$

\footnotetext{
${ }^{30}$ See Murphy (1998).
} 
Proposition 7 If $f$ is convex, $V_{f} \leq V_{\text {lin }}$; if $f$ is concave, $V_{f} \geq V_{\text {lin }}$.

$\mathbf{P}$ roof. The result follows from Jensen's inequality.

Intuitively, a contract with a convex incentive zone is never more valuable to an executive than an otherwise identical contract with a linear incentive zone; the opposite is true for a contract with a concave incentive zone. Let us specialize to $f\left(S_{T}\right)=S_{T}^{2}$ (Figure 7). In this case, ex-ante value of the cash bonus contract, denoted by $V_{2}$, reads:

$$
V_{2}=B_{l} C_{B}\left(S_{0}, r, \sigma, T, K=S_{l}\right)+\frac{B_{u}-B_{l}}{S_{u}^{2}-S_{l}^{2}}\left(C_{2}\left(S_{0}, r, \sigma, T, K=S_{l}^{2}\right)-C_{2}\left(S_{0}, r, \sigma, T, K=S_{u}^{2}\right)\right)
$$

where $C_{2}$ is:

$$
C_{2}\left(S_{0}, r, \sigma, T, K\right)=S_{0}^{2} e^{\left(r T+\sigma^{2} T\right)} N\left(d_{3}\right)-K e^{-r T} N\left(d_{2}\right)
$$

and

$$
\begin{aligned}
& d_{1}=\frac{\ln \left(\frac{S_{0}}{K}\right)+\left(r+\frac{1}{2} \sigma^{2}\right) T}{\sigma \sqrt{T}} \\
& d_{2}=d_{1}-\sigma \sqrt{T} \\
& d_{3}=d_{1}+\sigma \sqrt{T}
\end{aligned}
$$

A comparative statics analysis can be performed just like in the case of the linear incentive zone (Section 3). In particular, one can show that, upon substituting $V_{\text {lin }} \rightarrow V_{2}$, Proposition 1, Proposition 5 \{Parts a) and b)\} and Proposition 6 remain valid. This, in part, implies that when the incentive domain $S_{u}-S_{l}$ is sufficiently small, the executive's attitude towards risk will depend only on the values of the boundary points and not on the shape of the incentive zone. At the limit, the shape of the value function for $V_{2}$ is virtually identical to the shape of the value function for $V_{\text {lin }}$ (the same is true for a general concave or convex $f$ ).

On the other hand, from Figure 8, one can see that when the incentive domain $S_{u}-S_{l}$ is not very small, the shape of the incentive zone can significantly influence the executive's attitude towards risk. Here, a Type IIb contract is plotted. In this case, the executive facing a linear incentive zone will avoid taking any risk (Proposition 5, part c), while her counterpart facing a contract with the convex zone will optimally select a non-zero level of risk.

Utilizing Equation 8, it is not difficult to show that pay-performance sensitivity \{see Jensen and Murphy (1990)\} is smaller in the convex case than in the linear case, i.e., that $\frac{\partial V_{2}}{\partial S_{0}}<\frac{\partial V_{l i n}}{\partial S_{0}}$. Therefore, contracts with convex incentive zones do not improve pay-performance incentives when compared to contracts with linear incentive zones, ceteris paribus. They do, however, increase the likelihood that in-the-money contracts will be "optimal" from the executive's standpoint. The argument reverses when the incentive zone is concave. 


\subsection{The Valuation of Performance Share Contracts}

Performance share contracts are discussed, for example, in Conyon and Murphy (2000). ${ }^{31}$ These contracts promise to deliver a number of company shares at maturity, conditional on the executive's meeting the performance threshold and vesting requirement. Such contracts differ from the standard cash bonus in two ways: first, the payoff is in shares rather than in cash; second, since the contract length is usually three to six years, vesting risk becomes an issue.

Performing an ex-post valuation for the performance share packages of British executives, Conyon and Murphy (2000) assume that the pay-performance sensitivity of such contracts is equal to one, independently of the contract features. An ex-ante valuation approach allows us to obtain an exact analytical expression for the pay-performance sensitivity of such contracts. The simplest performance share contract promises the delivery, at maturity, of one share of the company's stock if a performance target has been met and the executive stays in the company. If the performance threshold is $S_{l}$, the contract payoff at maturity is:

$$
\operatorname{Payoff}(T)=S_{T} \mathbf{1}_{\left\{S_{T} \geq S_{l}\right\}}=S_{l} \mathbf{1}_{\left\{S_{T} \geq S_{l}\right\}}+\max \left(S_{T}-S_{l}, 0\right)
$$

and the contract value, at origination, is equal to (here we, for simplicity, assume that the executive stays in the company with certainty):

$$
V=S_{l} C_{B}\left(S_{0}, r, \sigma, T, K=S_{l}\right)+C\left(S_{0}, r, \sigma, T, K=S_{l}\right)=S_{0} N\left(d_{1}\left(K=S_{l}\right)\right)
$$

From Equation (9), it is easy to check that the pay-performance sensitivity of the contract is $\frac{\partial V}{\partial S_{0}}=N\left(d_{1}\left(K=S_{l}\right)\right)+\frac{n\left(d_{1}\left(K=S_{l}\right)\right)}{\sqrt{\sigma^{2} T}}$. In Figure 9, we plot $\frac{\partial V}{\partial S_{0}}$ for various values of volatility and the performance target. We point out that $\frac{\partial V}{\partial S_{0}}$ can be well below one, as well as well above one. In light of this, arbitrarily fixing the performance sensitivity of such contract to unity certainly does not seem innocuous.

More generally, in a linear performance shares contract, the contract delivers $L_{l}$ shares of the company stock if the performance measure reaches the minimal value $S_{l}$; exceeding $S_{l}$ increases the number of shares in a linear fashion until it caps at $L_{u}$ shares, when the performance measure reaches $S_{u}$. Since the contract payoff at maturity is:

$$
\operatorname{Payoff}(T)=L_{l} S_{T} \mathbf{1}_{\left\{S_{T} \geq S_{l}\right\}}+\frac{L_{u}-L_{l}}{S_{u}-S_{l}} S_{T}\left(\max \left(S_{T}-S_{l}, 0\right)-\max \left(S_{T}-S_{u}, 0\right)\right)
$$

the value of a linear incentive zone performance shares contract is given by the following

\footnotetext{
${ }^{31}$ Performance share contracts are very common in the UK, where they are often called "Long-Term Incentive Plans".
} 
expression:

$$
\begin{aligned}
V_{\text {lin }, \text { perf }}= & L_{l} S_{0} N\left(d_{1}\left(K=S_{l}\right)\right)+\frac{L_{u}-L_{l}}{S_{u}-S_{l}} S_{0}^{2} \exp \left(r T+\sigma^{2} T\right)\left(N\left(d_{3}\left(K=S_{l}\right)\right)-N\left(d_{3}\left(K=S_{u}\right)\right)\right) \\
& +\frac{L_{u}-L_{l}}{S_{u}-S_{l}} S_{0}\left(S_{u} N\left(d_{1}\left(K=S_{u}\right)\right)-S_{l} N\left(d_{1}\left(K=S_{l}\right)\right)\right)
\end{aligned}
$$

From this expression, one can easily discern the optimal risk-taking behavior of the executive, as well as the pay-performance incentive of the contract.

For long term contracts like this, with a maturity date three to six years from origination, the vesting risk, i.e., the risk related to the possibility of the executive's premature departure, can be very substantial. Incorporating vesting risk into the performance share contract valuation can be done in the manner similar to ESO valuation, namely, by introducing an executive's departure hazard rate $\lambda_{t}{ }^{32}$ The probability that the executive will stay in the company until the maturity date $T$ is given by $\operatorname{Pr}(\tau \geq T)=\exp \left(-\int_{0}^{T} \lambda_{t} d t\right) \cdot{ }^{33}$ In order to value such contracts one proceeds in two steps. First, the contract value is determined as if vesting occurs with certainty, using the same techniques as the above. Then, the result is multiplied by the probability of the executive's stay. How significant is the second factor? As a numerical example, let $\lambda$ be a constant equal to 0.25 , which corresponds to an executive's expected stay of four years. If $T=3$ years, the probability of staying in the company until vesting is lower than $50 \%$. Therefore, the vesting risk makes the contract less than half as valuable than it would be if the contract were to vest immediately, ceteris paribus. Clearly, ignoring vesting risk can lead to a substantial overestimation of the contract value.

\subsection{Ex-ante Versus Ex-post Valuation}

It is a common practice in most, if not all, empirical studies on the subject of executive compensation to use the ex-post instead of ex-ante values of cash bonus contracts. If the contract paid off the maximum allocated amount $B_{u}$, an ex-post value would overestimate the real (ex-ante) value of the package. ${ }^{34}$ The ratio $\frac{V_{l i n}}{B_{u} e^{-r T}}$ is a measure of an upper limit of such overestimation. Table 6 shows this ratio for different values of the parameters. ${ }^{35}$

We observe that the ratio is, in general, significantly less than one but greater than zero. If the bonus ends up out of the money, the ex-post contract value would be zero. Its ex-ante (real) value, on the other hand, is greater than zero. While it is an open empirical question whether under- and overestimation cancel each other out on average, depending on the different share

\footnotetext{
${ }^{32}$ See Jennergren and Naslund (1993), Cuny and Jorion (1995) or Carr and Linetsky (1999).

${ }^{33}$ Here, we assume that the timing risk is not priced and that probability of departure does not depend on the executive's performance. Relaxing these assumptions is possible \{see El Karoui and Martellini (2000)\}.

${ }^{34}$ Neglecting the vesting risk can cause additional overestimation.

${ }^{35}$ We use the same set of parameters as in Tables 3 and 4.
} 


\begin{tabular}{cccccc}
\hline$B_{u}-B_{l}$ & 0.1 & 0.2 & 0.3 & 0.4 & 0.5 \\
\hline$\frac{V_{l i n}}{B_{u} e^{-r T}}$ for $S_{0}=107$ & 0.245 & 0.266 & 0.287 & 0.309 & 0.330 \\
$\frac{V_{l i n}}{B_{u} e^{-r T}}$ for $S_{0}=117$ & 0.368 & 0.392 & 0.417 & 0.441 & 0.465 \\
$\frac{V_{l i n}}{B_{u} e^{-r T}}$ for $S_{0}=127$ & 0.494 & 0.519 & 0.544 & 0.569 & 0.594 \\
\hline \hline
\end{tabular}

Table 6: Ex-Ante Versus Ex-Post Value

price scenarios, it is clear that the common practice of using ex-post cash bonus values may potentially lead to substantial mis-specification in empirical studies.

In the absence of a complete empirical bonus valuation method, it may actually make sense to use the expected, rather than realized, payoffs of the bonus package, adjusting them where needed for the possibility of the executive's departure. ${ }^{36}$ One should bear in mind, however, that even in this case a well-defined pay-performance sensitivity measure does not exist. For that, we do need an ex-ante formula.

\section{Conclusion}

Techniques used in the literature for valuing compensation packages are often not self-consistent: while cash bonuses are valued ex-post, i.e., by taking a discounted value of the realized cash grants, employee stock options (ESOs) are valued ex-ante, i.e., before uncertainties are resolved. From a theoretical point of view, ex-ante valuation has several advantages: it is forward looking; it incorporates in principle all relevant risk factors; it utilizes well-known option pricing methods; and it provides a useful framework for analyzing agency problems. This last point is quite significant, yet typically overlooked: pay-performance sensitivity measures, such as the one discussed in Jensen and Murphy (1990) for stock options simply cannot be well-defined if the performance is measured ex-post. Despite its obvious merits, the topic of the ex-ante valuation of cash bonus grants has been unexplored in the literature until now, primarily because the ex-post approach is much simpler, even if not entirely correct, to use in empirical studies

The aim of this paper is to initiate the development of a comprehensive (ex-ante) valuation framework for the cash bonus contracts, a missing link in developing a consistent valuation approach towards valuing executive grants. We first remark that a typical executive cash bonus package has a payoff structure equivalent to that of a portfolio of European call and binary call options. If the performance of a risk-neutral executive is measured by the company stock price, the value of a bonus package is the amount that a well-diversified outside investor would be willing to pay for such a contingent claim. Under the standard set of assumptions, the value

\footnotetext{
${ }^{36}$ Variants of an such approach are commonly used among compensation practitioners. Even though such specification neglects the underlying option structure of a contract, it seems better than discounting the realized values.
} 
of such grant can be expressed as a linear combination of Black and Scholes calls and binary call prices, with the strike prices equal to the boundary points of the incentive zone.

The existence of a closed-form solution facilitates comparative statics analysis and the exploration of the related agency problems. Assuming that an executive can influence the stock price volatility by selecting different projects at origination, we show that when the incentive zone is linear, only deeply-out-of-the-money contracts and contracts with a large incentive range (i.e., a large difference between the maximum and minimum bonus payoffs) motivate the manager to take non-zero (and finite) levels of risk. We determine an analytical expression for the pay-performance sensitivity of a contract with a linear incentive zone. This quantity is always positive and, for a range of reasonable values of parameters, quite small in comparison with the pay-performance sensitivity of a stock option. In addition, we demonstrate that ex-ante and ex-post valuation techniques may potentially lead to very different results.

We generalize our discussion to bonus contracts with non-linear incentive zones. After demonstrating that, ceteris paribus, contracts with a convex (concave) incentive zone are always less (more) valuable than contracts with a linear incentive zone, we show by way of an example that the shape of the incentive zone can influence the executive's risk-taking behavior when the incentive domain (i.e., the difference between the upper and lower performance bounds) is sufficiently large. We, also, consider contracts where the payment is not in cash, but in company stock (the so-called performance share contracts).

Ex-ante valuation is the natural framework for valuing contracts with vesting risk. We show that long-term cash bonus contracts with vesting risk have smaller values than corresponding contracts with no vesting risk. This raises additional concerns that the commonly used expost bonus valuation techniques, plagued by some "survivorship" bias, may lead to serious mis-specification problems.

All this points to the need for development of the ex-ante valuation techniques, as well as learning how to apply them effectively in empirical studies. Before a practical procedure for the ex-ante valuation of cash-bonus contracts can be completely established, it is necessary to address several important issues that have been omitted in this paper. Since most cash bonus contracts measure performance using accounting variables, an ex-ante valuation method for this case must be developed first. It would be, also, desirable to obtain a better understanding of the difference between the value of a compensation package for an poorly diversified, riskaverse manager and the cost to a well-diversified shareholder of the company. ${ }^{37}$

At the end of Section 3.2., we outlined an agency problem related to bonus contracts: the trade-off (in general) between the maximal pay-performance incentive, and the optimal risk level that an unconstrained executive would take. An analysis similar to that found in Hall and

\footnotetext{
${ }^{37}$ See Martellini and Urošević (2001) for an attempt to address these questions within a standard consumption-based dynamic asset pricing model.
} 
Murphy (2000) for the optimal stock option exercise price could be used to determine the set of contract parameters that ensure the optimal trade-off between the two opposing interests. In addition, we have excluded from consideration in this paper other contract types, such as stock options.

\section{References}

Black, F., and Scholes, M., 1973, The Pricing of Debt and Corporate Liabilities, Journal of Political Economy, 81, pp. 637-659.

Cadenillas, A., Cvitanic, J., and Zapatero, F., 2001, Executive Stock Options with Effort Disutility and Choice of Volatility, working paper, USC.

Carpenter, J., 1998, The Exercise and Valuation of Executive Stock Options, Journal of Financial Economics, 48, pp. 127-158.

Carpenter, J., 2000, Does Option Compensation Increase Managerial Risk Appetite?, Journal of Finance, 55(6), 2311-2331.

Carr, P., and Linetsky, V., 1999, The Valuation of Executive Stock Options in an IntensityBased Framework, Working Paper.

Conyon, M., and K. Murphy, 2000, Stock-based Executive Compensation, Working Paper, USC.

Cuny, C., and Jorion, P., 1995, Valuing Executive Stock Options With Endogenous Departure, Journal of Accounting and Economics, 20, pp. 193-205.

Duffie, D., 1995, Dynamic Asset Pricing Theory, Princeton University Press.

El Karoui, N., and L., Martellini, 2000, A Theoretical Investigation of the Market Price for Default Risk, Working Paper, USC.

Garen, J., 1994, Executive Compensation and Principal-Agent Theory, Journal of Political Economy, 102(6), pp. 1175-1199.

Gaver, J., Gaver, K., and Austin, J., 1995, Additional Evidence on Bonus Plans and Income Management, Journal of Accounting and Economics, 19, pp. 3-28.

Hall, B., and Murphy, K., 2000, Stock Options for Undiversified Executives, Working Paper, USC.

Hall, B., and Murphy, K., 2000, Optimal Exercise Prices for Employee Stock Options, American Economic Review, May 2000.

Hermalin, B. and Wallace, N., 1999, Firm Performance and Executive Compensation in the Savings and Loan Industry, Working Paper, Journal of Financial Economics, forthcoming.

Holmstrom, B., 1979, Moral Hazard and Observability, The Bell Journal of Economics, 10, pp. 74-91. 
Holthausen, R., Larcker, D., and Sloan, R., 1995, Annual Bonus Schemes and the Manipulation of Earnings, Journal of Accounting and Economics, 19(1), pp. 29-74.

Jennergern, P., and Naslund B., 1993, A Comment on "Valuation of Executive Stock Options and the FASB Proposal", The Accounting Review, 68(1), pp. 179-183.

Jensen, M., and Meckling, W., 1976, Theory of the Firm: Managerial Behavior, Agency Costs and Ownership Structure, Journal of Financial Economics, 3, pp. 305-360.

Jensen, M., and Murphy, K., 1990, Performance Pay and Top-Management Incentives, Journal of Political Economy, 98, pp. 225-264.

Jiang, W., 2000, Incentives for Money Managers under Endogenous Risk Choice, University of Chicago, Department of Economics working paper.

Johnson, S. and Tian, Y., 2000a, The Value and Incentive Effects of Nontraditional Executive Stock Option Plans, Journal of Financial Economics, 57, pp 3-34.

Johnson, S. and Tian, Y., 2000b, Indexed Executive Stock Option Plans, Journal of Financial Economics, 57, pp 35-64.

Kole, S., 1997, The Complexity of Compensation Contracts, Journal of Financial Economics, 43, pp.79-104.

Lambert, R., Larcker, D., and Verrecchia, R., 1991, Portfolio Consideration in Valuing Executive Compensation, Journal of Accounting Research, 29(1).

Martellini, L., and Urošević, B., 2001, A Consumption-Based Asset Pricing Approach to the Valuation of Compensation Packages, Working Paper, USC.

Martellini, L., Urošević, B., and Wonder, N., 2001, Principal-Agent Problem and the Endogenous Determination of Contract Terms for Complex Compensation Contracts, Working Paper, USC.

Meulbroek, L., 2000, The Efficiency of Equity-Linked Compensation: Understanding the Full Cost of Awarding Executive Stock Options, Working Paper, HBS.

Murphy, K., 1998, Performance Standards in Incentive Contracts, Working Paper.

Murphy, K., 1999, Executive Compensation, in Handbook of Labor Economics, III, Orley Ashenfelter and David Card, editors, North Holland.

Ross, S., 1999, Some Notes on Compensation, Agency Theory, and the Duality of Risk Aversion and Riskiness, MIT Sloan School working paper.

Urošević, B., 2000, Valuing Employee Compensation Packages, Ekonomski Anali (in English), 145, pp. 239-258.

Wilmott, P., 1998, Derivatives, John Wiley \& Sons. 


\section{Appendix}

Part a) in Proposition 1 follows from $\lim _{\sigma \rightarrow \infty} C=S_{0}$ and $\lim _{\sigma \rightarrow \infty} C=S_{0 B}=0$ since, in this case, the present value of the minimal bonus component vanishes, while the standard call components cancel each other out. A change in stock price volatility affects the value function through the cash bonus vega:

$$
\frac{\partial V}{\partial \sigma}=B_{l} \vartheta_{B}\left(K=S_{l}\right)+\frac{B_{u}-B_{l}}{S_{u}-S_{l}}\left(\vartheta\left(K=S_{l}\right)-\vartheta\left(K=S_{u}\right)\right)
$$

where vegas for the binaries and the standard calls are given by: ${ }^{38}$

$$
\begin{aligned}
\vartheta & \equiv \frac{\partial C}{\partial \sigma}=S_{0} \sqrt{T} n\left(d_{1}\right) \\
\vartheta_{B} & \equiv \frac{\partial C_{B}}{\partial \sigma}=-e^{-r T} n\left(d_{2}\right)\left(\frac{d_{1}}{\sigma}\right)
\end{aligned}
$$

Therefore, we obtain: ${ }^{39}$

$$
\begin{aligned}
\operatorname{sign}\left(\vartheta_{B}\right) & =-\operatorname{sign}\left(d_{1}\left(K=S_{l}\right)\right) \\
\operatorname{sign}\left(\vartheta\left(K=S_{l}\right)-\vartheta\left(K=S_{u}\right)\right) & =-\operatorname{sign}(x) \\
x & \equiv 2 d_{1}\left(S_{l}\right)+\frac{\ln \left(\frac{S_{l}}{S_{u}}\right)}{\sigma \sqrt{T}}
\end{aligned}
$$

Part c) is immediate from Equation 11 since, if $S_{0} \geq S^{*}=\sqrt{S_{u} S_{l}} e^{-r T}$, we also have $S_{0} \geq \sqrt{S_{u} S_{l}} e^{-\left(r+\frac{\sigma^{2}}{2}\right) T}$ for every $\sigma$, which in turn implies that $x \geq 0$ and $d_{1}\left(K=S_{l}\right)>0$. From Proposition 1 and Equations 10 and 11, it follows that $\frac{\partial V}{\partial \sigma}<0$ for all $\sigma$. The proof of parts b) and d) are very similar.

\footnotetext{
${ }^{38}$ See Willmott (1998).

${ }^{39}$ Inequality $\vartheta\left(K=S_{l}\right)>\vartheta\left(K=S_{u}\right)$ implies that $n\left(K=S_{l}\right)>n\left(K=S_{u}\right)$, which in turn implies that $d_{1}^{2}\left(K=S_{u}\right)-d_{1}^{2}\left(K=S_{l}\right)>0$, which can be easily seen to imply $x<0$. Conversely, $\vartheta\left(K=S_{l}\right)<\vartheta\left(K=S_{u}\right)$ implies that $x>0$.
} 